\title{
Editorial
}

\section{A interdisciplinaridade neste começo de século}

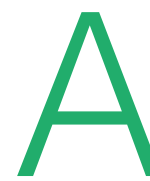
ciência do século XXI prima pela interdisciplinaridade, como se pode observar nos congressos nacionais e internacionais. Assim, a RBAV traz nessa edição vários artigos selecionados no III CIMATECH - Congress of Industrial Management Aeronautical Technology, um encontro com foco em Engenharia de Produção e trabalhos muito interessantes nas áreas de simulação, materiais, construção de protótipos, dentre outras. Tudo que a nossa boa e velha Tecnologia de Vácuo sempre colaborou para desenvolver. Esta edição retrata esta abordagem interdisciplinar, eminentemente prática, mas com fortes e sólidos conceitos teóricos.

A Tecnologia de Vácuo, per se, não tem apresentado grandes inovações que tenham tido destaque nos últimos tempos. Continua sendo básica para a realização de inúmeras medições e avanços nas mais diversas áreas do conhecimento. Sempre foi e continua sendo o objetivo desta Revista, a divulgação de trabalhos que tenham a Ciência e a Tecnologia de Vácuo como ferramenta, ainda que indiretamente, para a obtenção de seus resultados.

Álvaro Jose Damião

Antonio Renato Bigansolli

Maria Lúcia Pereira da Silva 